\title{
VEGF siRNA delivered by polycation liposome- encapsulated calcium phosphate nanoparticles for tumor angiogenesis inhibition in breast cancer
}

This article was published in the following Dove Press journal:

International Journal of Nanomedicine

21 August 2017

Number of times this article has been viewed

\author{
Jinliang Chen' \\ Xiaoyi Sun ${ }^{2}$ \\ Rong Shao' \\ Yichao Xu' \\ Jianqing $\mathrm{Gao}^{3}$ \\ Wenquan Liang ${ }^{3}$ \\ 'Center of Clinical Pharmacology, \\ The Second Affiliated Hospital \\ of Zhejiang University, School of \\ Medicine, ${ }^{2}$ Department of Pharmacy, \\ Zhejiang University City College, \\ ${ }^{3}$ Institute of Pharmaceutics, College \\ of Pharmaceutical Sciences, Zhejiang \\ University, Hangzhou, Zhejiang, \\ People's Republic of China
}

\begin{abstract}
Angiogenesis plays an important role in tumor development and metastasis, and many cancer cells upregulate VEGF expression to promote angiogenesis. Silencing VEGF expression by RNA interference is expected to be a promising strategy to suppress the tumor growth. However, low transfection efficiency and instability are the main barriers for small interfering RNA (siRNA) delivery. In this study, we developed polycation liposome-encapsulated calcium phosphate nanoparticles (PLCP) for siRNA delivery in vivo. VEGF expression silencing effect in MCF-7 cells was investigated by real-time quantitative polymerase chain reaction and Western blot assay. VEGF siRNA mediated by PLCP can reduce $60 \%-80 \%$ VEGF expression in vitro, which was significantly higher than that mediated by Lipofectamine 2000. Furthermore, significant tumor growth and angiogenesis inhibition were observed in MCF-7 xenografts mice when treated with PLCP/VEGF siRNA or combined with doxorubicin. In conclusion, the combination of silencing VEGF expression and chemotherapeutics would be a potential treatment for cancer therapy.
\end{abstract}

Keywords: polycation liposomes, calcium phosphate nanoparticles, VEGF, siRNA, angiogenesis inhibition

\section{Introduction}

Angiogenesis, one of the major hallmarks of cancer, plays an important role in vasculature establishment for growth and hematogenous metastasis. ${ }^{1}$ In angiogenesis, there is a change from normal recruitment of endothelial progenitor cells to pathologic sprouting of new vessels. ${ }^{2}$ Specified cytokines and growth factors secreted by tumor cells and stromal cells stimulate proliferation of vascular endothelial cell. ${ }^{3}$ Among these factors, VEGF, upregulated by many cancer cells, is known as closely associated with increased aggressiveness and metastasis. ${ }^{4}$ Clinical studies have indicated that VEGF can be targeted to reduce angiogenesis, and VEGF inhibition has been shown to promote survival and slow tumor growth in ovarian, cervical, colorectal, renal, lung, and breast cancers. ${ }^{5}$

RNA interference, a highly conserved gene silencing mechanism, is one of the most widely used procedures for gene targeting in cutting edge technology and has potential for use in clinical therapy. ${ }^{6}$ Many diseases are caused by the inappropriate expression of disease-related genes, including cancer, obesity, heart disease, and diabetes. ${ }^{7,8}$ Small interfering RNA (siRNA) treatments represent advantages over conventional ones because of their powerful and highly specific gene silencing ability. ${ }^{9}$ Synthetic siRNA mediates target gene silencing by promoting mRNA degradation in the cytoplasm.
Correspondence: Jinliang Chen Center of Clinical Pharmacology, The Second Affiliated Hospital, School of Medicine, Zhejiang University, Jiefang Road 88, Hangzhou, Zhejiang 310009, People's Republic of China

Tel +8657 I 87783759

Fax +86 57I 87783969

Email chenjinliang@zju.edu.cn 
However, low transfection efficiency and poor stability in physiological conditions are the main obstacles for siRNA delivery in clinical application.

The development of safe and effective siRNA delivery system would enhance the clinical application of gene silencing siRNA in cancer therapy. Several approaches have been used to overcome the obstacle of siRNA delivery, including complexation, entrapment, and conjugation, most of which were based on a lipidic or polymeric scaffold. Cationic lipid-based vectors have several advantages including stability and favorable cellular internalization, while toxicity and protection of siRNA can be major challenges. ${ }^{10,11}$ Various polymeric nanoparticles have also been explored for siRNA delivery, such as polyethylenimine (PEI), ${ }^{12}$ chitosan, ${ }^{13}$ and dendrimers. ${ }^{14}$ Polymer-based complexes have been shown to protect siRNA from degradation, to mediate cellular uptake, and to efficiently promote lysosomal protection and escape into the cytoplasm. However, their strongly positive charge promotes the colloidal instability in vivo and leads to difficult dissociation of siRNA from complexes. Calcium phosphate (CaP) has been developed for the delivery of DNA since 1970 s and was used for siRNA delivery in recent years. CaP shows negligible cytotoxicity for siRNA delivery due to its inherent biocompatibility and biodegradability. In addition, $\mathrm{CaP}$ can be dissolved in the acidic endosome to help siRNA release into the cytosol- and silence-specific genes. ${ }^{15}$

In our previous study, we have developed a siRNA delivery system, polycation liposome-encapsulated calcium phosphate nanoparticles (PLCP), using CaP/siRNA nanoparticles combined with polycation liposomes (PCLs). ${ }^{16} \mathrm{PCL}$ was developed to improve the ability of endosomal escape by combining the protonation of PEI and the membrane destabilization of 1,2-dioleoyl-sn-glycero-3-phosphoethanolamine (DOPE), which led to high transfection efficiency. When encapsulating $\mathrm{CaP}$, PCL could control the growth of $\mathrm{CaP}$ precipitates, which would lead to large aggregation and reduce stability. Anti-green fluorescent protein (GFP) siRNA transferred by PLCP to MCF-7 cells that stably express GFP represented high gene silencing efficiency with low cytotoxicity. In this study, we further investigated the VEGF siRNA delivery efficiency of PLCP both in vitro and in MCF-7 xenograft mice. Tumor inhibition ratio and angiogenesis status were assessed. In addition, synergetic tumor inhibition effect combined with doxorubicin (DOX) was also studied.

\section{Materials and methods}

\section{Materials}

Pluronic F68 and DOPE were purchased from Sigma-Aldrich (St Louis, MO, USA). PEI-cholesterol (PEI-Chol) was synthesized as previously reported. ${ }^{17}$ Dulbecco's Modified Eagle's Medium (DMEM), trypsin, fetal bovine serum (FBS), and Lipofectamine 2000 were purchased from Thermo Fisher Scientific (Waltham, CA, USA). DOX hydrochloride was kindly provided by Hisun Pharmaceutical Co. Ltd. (Taizhou, Zhejiang, China). Random siRNA and VEGF siRNA were synthesized, modified, and purified by 100 Biotech Company (Hangzhou, Zhejiang, China). All other chemical reagents were of analytical grade from Sinopharm Chemical Reagent Company (Shanghai, China).

\section{Preparation of PLCP}

$\mathrm{CaP} /$ siRNA nanoparticles were prepared as previously reported. ${ }^{16}$ Briefly, $\mathrm{CaCl}_{2}$ (75 mM), Pluronic F68 (1\%), and siRNA solution $(0.1 \mathrm{mg} / \mathrm{mL})$ were mixed and incubated for 10 min. $\mathrm{Na}_{2} \mathrm{HPO}_{4}(6 \mathrm{mM})$, Pluronic F68 (1\%), and sodium citrate $(24 \mathrm{mM})$ were mixed and added to an equal volume of abovementioned solution dropwise under stirring for $30 \mathrm{~min}$. The mass ratios of $\mathrm{CaCl}_{2}$ and siRNA were studied by gel retardation assays. CaP/siRNA nanoparticles $(15 \mu \mathrm{L})$ with different mass ratios (ranging from 1 to 25) were loaded onto a $0.5 \%$ agarose gel. Free siRNA was used as a control. Electrophoresis was performed at $90 \mathrm{~V}$ for $60 \mathrm{~min}$. The gel was visualized by ethidium bromide staining.

PCLs were prepared by film dispersion method ${ }^{18}$ with a lipid mixture of PEI-Chol and DOPE (molar ratio 1:1), and then hydrated with $\mathrm{CaP}$ nanoparticle solution followed by sonication and filtration through $0.22 \mu \mathrm{m}$ filter. PLCP were constructed of $\mathrm{CaP} / \mathrm{siRNA}$ nanoparticles as inner aqueous phase and PCL as outer lipid layer. The N/P ratio (1 mol PEI-Chol per mole siRNA phosphate) of PCL and $\mathrm{CaP} /$ siRNA was 20. Particle size was measured by laser diffraction spectrometry (Zetasizer 3000HS, Malvern Instruments, Malvern, UK). Morphologies of PLCP were observed by transmission electron microscopy (TEM, JEM-1200EX, JEOL Ltd., Tokyo, Japan).

\section{Cell culture and gene silencing assay in vitro}

Human breast adenocarcinoma cell lines (MCF-7) were obtained from the Institute of Biochemistry and Cell Biology, Shanghai Institutes for Biological Sciences (Shanghai, China). MCF-7 cells were cultured in DMEM containing $10 \% \mathrm{FBS}$ at $37^{\circ} \mathrm{C}$ in $5 \% \mathrm{CO}_{2}$. Cells were regularly passaged and reseeded $24 \mathrm{~h}$ before gene silencing experiments. In order to evaluate the gene silencing ability, three different VEGF siRNA sequences were synthesized (Table 1), which were mediated by PLCP and Lipofectamine 2000. For gene silencing experiments, $1.5 \times 10^{4} \mathrm{MCF}-7$ cells were seeded with $2 \mathrm{~mL}$ of DMEM containing $10 \% \mathrm{FBS}$ on 
Table I Sequence of siRNA

\begin{tabular}{lll}
\hline siRNA & Sense & Antisense \\
\hline Random siRNA & 5'-UCCUCCGAACGUGUCACGUTT-3' & 5'-ACGUGACACGUUCGGAGAATT-3' $^{\prime}$ \\
VEGF siRNA-1 & 5'-CCGAAACCAUGAACUUUCUTT-3' & 5'-AGAAAGUUCAUGGUUUCGGTT-3' \\
VEGF siRNA-2 & 5'-GGCAGAAUCAUCACGAAGUTT-3' & 5'-ACUUCGUGAUGAUUCUGCCTT-3' \\
VEGF siRNA-3 & 5'-GCUUCCUACAGCACAACAATT-3' & 5'-UUGUUGUGCUGUAGGAAGCTT-3' \\
\hline
\end{tabular}

Abbreviation: siRNA, small interfering RNA.

12-well plates. The next day, VEGF siRNA ( $1 \mu \mathrm{g}$ siRNA/ well) was transfected using Lipofectamine $2000(5 \mu \mathrm{L})$ and PLCP $(\mathrm{N} / \mathrm{P}=20)$ into cells for $5 \mathrm{~h}$, and then the medium was replaced with fresh medium. Cells were harvested, and the RNA was extracted using Trizol reagent (Thermo Fisher Scientific), reverse-transcribed to cDNA, and amplified by polymerase chain reaction (PCR). The following PCR conditions were used: initial denaturation at $95^{\circ} \mathrm{C}$ for $3 \mathrm{~min}$, then $95^{\circ} \mathrm{C}$ for $12 \mathrm{~s}, 62^{\circ} \mathrm{C}$ for $40 \mathrm{~s}$ for 40 cycles. The related VEGF mRNA expression was determined after $24 \mathrm{~h}$ by real-time quantitative PCR (RT-qPCR), using the $2^{-\Delta \Delta C T}$ quantitation method with hGAPDH (human glyceraldehyde-3-phosphate dehydrogenase) as a housekeeping gene. The primer sequences of human VEGFA (hVEGFA) and hGAPDH for amplifying are shown in Table 2.

The total protein was isolated $48 \mathrm{~h}$ posttransfection, and the expression level of VEGF was determined by Western blot assay. Cell extracts were prepared in lysis buffer, then transferred to sodium dodecyl sulfate-polyacrylamide gel $(10 \%)$ electrophoresis (SDS-PAGE), and the resolved proteins were transferred electrophoretically to polyvinylidene fluoride membranes (EMD Millipore, Billerica, MA, USA). The hGAPDH was used as loading control. Protein levels were quantified using Gel-Pro Analyzer 4.0 software and normalized to the levels of hGAPDH.

\section{Tumor and angiogenesis inhibition in vivo}

The animal experiment was in accordance with Zhejiang University guidelines for the welfare and ethics of the experimental animals, and the protocol was reviewed and approved by the Institution Animal Ethics Committee (The Second Affiliated Hospital of Zhejiang University, School of Medicine). BALB/C-nu female mice (4-6 weeks) were obtained from Laboratory Animals Central of Academy of

Table 2 Primer sequences of hVEGFA and hGAPDH

\begin{tabular}{lll}
\hline Gene & Sequence & \\
\hline hVEGFA & F primer & GGCAGAATCATCACGAAGTGGTG \\
& P primer & GGGTCTCGATTGGATGGCAGTAG \\
hGAPDH & F primer & CATGAGAAGTATGACAACAGCCT \\
& P primer & AGTCCTTCCACGATACCAAAGT \\
\hline
\end{tabular}

Abbreviation: hGAPDH, human glyceraldehyde-3-phosphate dehydrogenase.
Military Medical Sciences and were maintained under a $12 \mathrm{~h}$ light $/ 12 \mathrm{~h}$ dark photoperiod for in vivo tumor inhibition experiments. Tumor xenografts were generated by injecting $1 \times 10^{6}$ MCF-7 cells in $0.2 \mathrm{~mL}$ DMEM subcutaneously into right forelimb armpit. When the tumors reached a size of $\sim 100 \mathrm{~mm}^{3}$ (Day 10 after inoculation), the mice were randomized into different treatment groups $(\mathrm{n}=5)$. Saline, PLCP, and PLCP with either the scrambled siRNA or the specific VEGF siRNA were intratumorally injected twice a week (0.5 nM siRNA, $100 \mu \mathrm{L})$. DOX was peritoneally injected once a week with a dosage of $2 \mathrm{mg} / \mathrm{kg}$. For the combination therapy (PLCP/VEGF siRNA and DOX), the dosage of DOX was reduced to $1.2 \mathrm{mg} / \mathrm{kg}$.

The body weight changes and physiological state of mice were recorded during the whole therapeutic period. Tumor volume was measured every 3 days after first administration and calculated by the formula: $\mathrm{V}=\pi \mathrm{ab}^{2} / 6$, where $\mathrm{a}$ is the maximum and $b$ is the minimum diameter of the tumor. At the end of the animal study (Day 28 after inoculation) or when tumor volume exceeded $1,000 \mathrm{~mm}^{3}$, mice were sacrificed and the tumors were excised and weighed. The tumor inhibition rate was calculated by the following formula: tumor inhibition ratio $=\left(\right.$ mean tumor weight ${ }_{(\text {Control })}-$ mean tumor

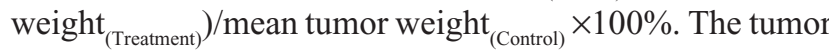
tissue samples were fixed, sectioned, and stained with antiCD34 to detect vascular endothelial cells. The areas of increased vascularity were chosen at $100 \times$ magnification, and the microvessel density (MVD) was calculated at $400 \times$ magnification (five views) according to the procedure reported by Weidner et al. ${ }^{19}$ In addition, VEGF and hypoxia-inducible factor- $1 \alpha(\mathrm{HIF}-1 \alpha)$ protein expression of tumor tissues were also assessed by immunohistochemistry.

The standard operation procedure was performed. The tumor tissues were fixed in $4 \%$ formaldehyde and embedded in paraffin. The paraffin section $(4 \mu \mathrm{m})$ was hydrated with xylene, $100 \%$ ethanol, $90 \%$ ethanol, $80 \%$ ethanol, $70 \%$ ethanol, and distilled water. Then, the sections were incubated with primary antibodies against CD34 (1:50), VEGF (1:200), or HIF-1 $\alpha(1: 500)$ overnight at $4^{\circ} \mathrm{C}$ individually. After incubation with secondary antibodies at room temperature for $15 \mathrm{~min}$, the expression was visualized by 3,3'diaminobenzidine tetrahydrochloride staining. Finally, the 
sections were counterstained with hematoxylin and dehydrated and observed with a microscope.

\section{Statistical analysis}

The data were presented as mean $\pm \mathrm{SD}$, and the statistical analysis was performed using Student's $t$-test for two groups or one-way analysis of variance for multiple groups. A $P$-value of 0.05 or less was considered significant.

\section{Results}

\section{Characteristics of PLCP}

The mean particle sizes of CaP nanoparticles, PCL, and PLCP were $30.6 \pm 2.5 \mathrm{~nm}$ polydispersity index (PDI 0.206), $234 \pm 22.6 \mathrm{~nm}$ (PDI 0.252), and 207 $\pm 17.5 \mathrm{~nm}$ (PDI 0.236), respectively. The size distribution is shown in Figure S1. Morphological characterization of PLCP was carried out using TEM. As shown in Figure 1A, CaP nanoparticles and PCLs were spherical in shape with smooth surface and uniform particle size correlating with the results of laser diffraction spectrometry. PLCP showed a core-membrane structure with $\mathrm{CaP}$ nanoparticles in inner aqueous phase. Due to flexibility of lipid bilayer, PLCP could encapsulate multiple $\mathrm{CaP}$ nanoparticles.

$\mathrm{CaP}$ nanoparticles can bind siRNA by electrostatic interactions. With the increasing mass ratio of $\mathrm{CaCl}_{2}$ and siRNA, the amount of unbound siRNA decreased as shown in gel retardation assays results (Figure 1B). The unbound siRNA strap disappeared when the mass ratio was 15 , which suggests that $\mathrm{CaP}$ nanoparticles can bind siRNA efficiently at that mass ratio. In this study, we used $\mathrm{CaP}$ nanoparticles with the mass ratio of 25 .

\section{VEGF inhibition in vitro}

The efficacy of PLCP-mediated siRNA delivery was investigated in MCF-7 cells. We constructed three different VEGF siRNA sequences targeting VEGF mRNA. PLCP, representing significantly higher VEGF mRNA silencing efficiency than Lipofectamine 2000 after $24 \mathrm{~h}$ transfection (Figure 2A). The lowest VEGF mRNA expression reached $19 \%$ when VEGF siRNA was mediated by PLCP, while 53\% VEGF

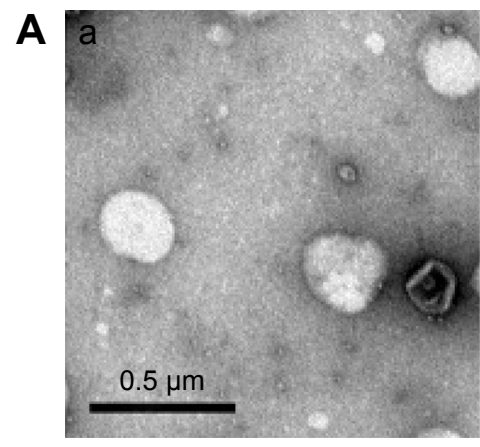

B
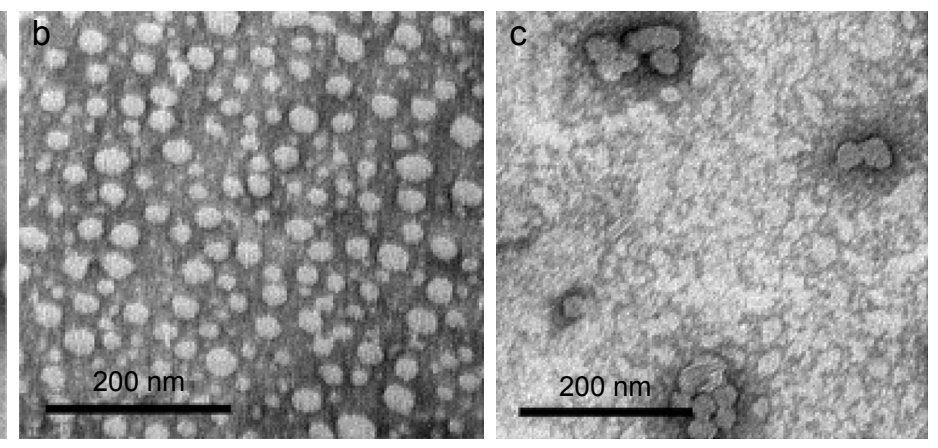

CaP nanoparticles

The mass ratio of $\mathrm{CaCl}_{2}$ and siRNA

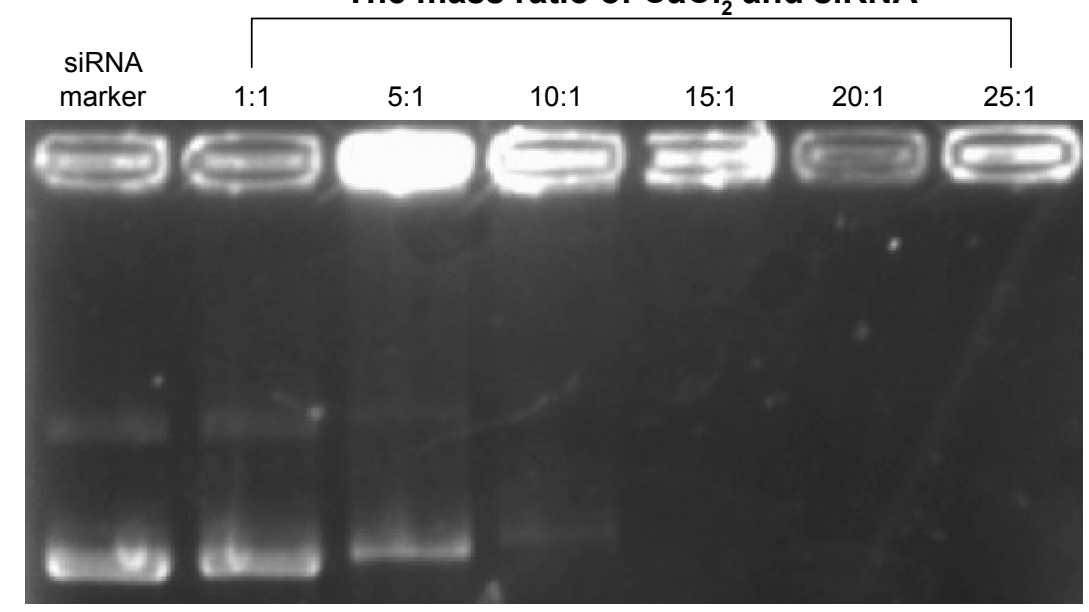

Figure I Images of transmission electron microscopy and gel retardation assays.

Notes: (A) Transmission electron microscopy analysis of PCL (a), CaP nanoparticles (b), and PLCP (c). (B) Gel retardation assays of CaP nanoparticles with various mass ratios of $\mathrm{CaCl}_{2}$ and siRNA.

Abbreviations: CaP, calcium phosphate; PCL, polycation liposome; PLCP, polycation liposome-encapsulated calcium phosphate nanoparticles; siRNA, small interfering RNA. 

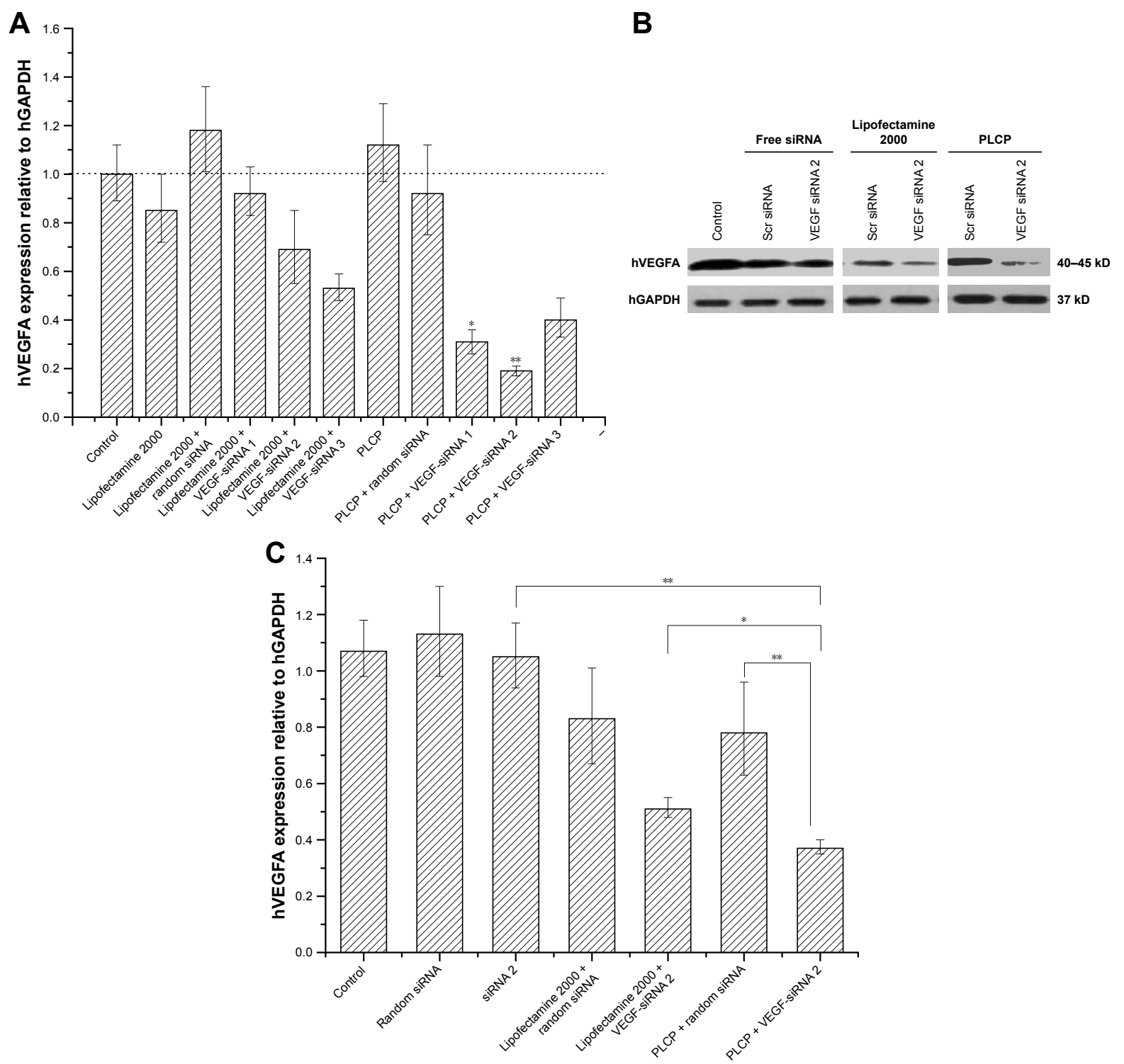

Figure 2 Gene silencing efficiency of VEGF-siRNA in MCF-7 cells.

Notes: (A) Relative expression levels of VEGF mRNA in MCF-7 cells determined by RT-qPCR after $24 \mathrm{~h}$ transfection. $* P<0.05$ (PLCP/VEGF-siRNA I vs Lipofectamine $2000 /$ VEGF-siRNA 3) and **P<0.01 (PLCP/VEGF-siRNA 2 vs Lipofectamine 2000/VEGF-siRNA 3). (B) VEGF protein expression relative to hGAPDH in MCF-7 cells determined by Western blot after $48 \mathrm{~h}$ transfection. (C) Semiquantitative gray scale results of Western blot. $* P<0.05$ and $* * P<0.01$. I $\mu \mathrm{g}$ siRNA/well.

Abbreviations: hGAPDH, human glyceraldehyde-3-phosphate dehydrogenase; PLCP, polycation liposome-encapsulated calcium phosphate nanoparticles; RT-qPCR, realtime quantitative polymerase chain reaction; siRNA, small interfering RNA; Scr, scramble.

mRNA expression was observed when it was mediated by Lipofectamine 2000. VEGF siRNA 2 showed the highest gene silencing efficacy, and little biological efficacy was found when cells were treated with random siRNA and blank carriers. The results indicated that gene silencing efficiency might be correlated with sequence specificity. Thus, VEGF siRNA 2 was chosen for the following Western blot determination. The amplification curves for RT-qPCR are shown in Figure S2.

After a $48 \mathrm{~h}$ transfection, VEGF protein level was determined using Western blot assay (Figure 2B) and converted to semiquantitative gray scale. As shown in Figure 2C, VEGF protein levels (63\% and 49\%) were obviously inhibited when VEGF siRNA 2 was mediated by PLCP and Lipofectamine 2000, respectively. These results were similar to those of RT-qPCR. The comparison between negative control group and blank carrier groups revealed the absence of nonspecific effects.

\section{Tumor growth inhibition in vivo}

To evaluate the tumor inhibition efficacy of VEGF siRNA mediated by PLCP and combined treatment with DOX on MCF-7 xenograft in mice, tumor volumes were measured 
every 3 days after first administration, and tumor tissues were weighed after excising. Considering animal ethics, mice were sacrificed when tumor volume exceeded $1,000 \mathrm{~mm}^{3}$. Figure 3A shows that tumor volume grew fast in saline, PLCP, and PLCP/scramble (Scr) siRNA groups. The final tumor volume reached 1,145 $\mathrm{mm}^{3}$ (saline), 1,067 $\mathrm{mm}^{3}$ (PLCP), and 1,204 $\mathrm{mm}^{3}$ (PLCP/Scr siRNA), respectively, which were significantly larger than treatment groups. In contrast, the tumor volume was obviously inhibited after VEGF siRNA and DOX administration. After 28 days of inoculation, the tumor volumes of PLCP/VEGF siRNA group, DOX group, and PLCP/VEGF siRNA + DOX group were $356 \mathrm{~mm}^{3}$, $139 \mathrm{~mm}^{3}$, and $75 \mathrm{~mm}^{3}$, respectively. The tumor inhibition ratio was calculated by tumor weight (Figure 3B). Higher inhibition rates were observed in PLCP/VEGF siRNA $(\sim 72 \%)$ and DOX ( $~ 84 \%)$ groups compared with control and blank carrier groups. We also found that the combination therapy of VEGF siRNA and DOX may possess a more powerful ability on tumor inhibition ( $91 \%$ ). To evaluate the safety of PLCP, the body weight changes and physiological state of mice were recorded during the whole therapeutic period. No significant change in body weight was found (Figure 3C).

\section{Immunohistochemistry study}

Angiogenesis inhibition efficacy was evaluated by immunohistochemistry study. CD34 is the marker of vascular endothelial cells and CD34-positive cells displayed brown on the cytoplasm. Fewer immunoreactive microvessels were observed in the tumor tissue sections of VEGF siRNA-treated groups (Figure 4A). The MVD in VEGF siRNA group was about 58 microvessels/field of view, which was dramatically lower compared to saline (153 microvessels/field of view)

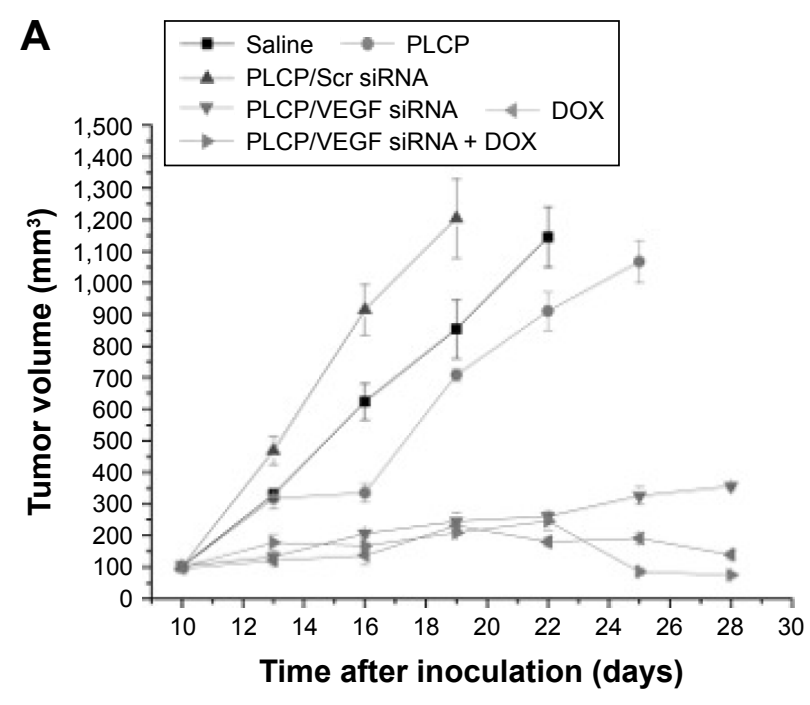

B
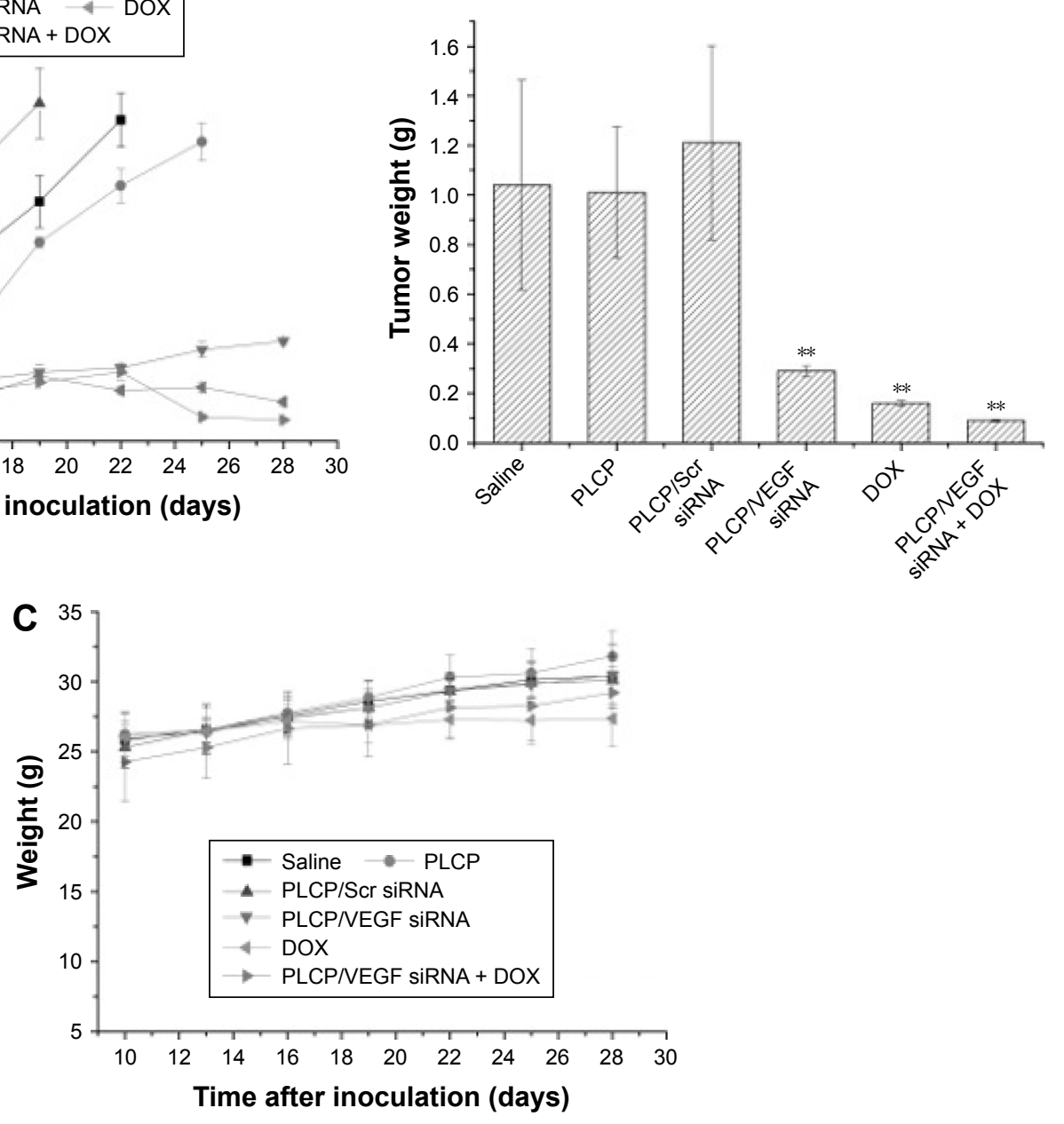

Figure 3 Tumor growth inhibition in vivo.

Notes: (A) Tumor growth curves of mice $(n=5)$. (B) Comparison of tumor weight among mice that received different treatments. $* * P<0.01$. (C) The changes in body weight. Abbreviations: DOX, doxorubicin; PLCP, polycation liposome-encapsulated calcium phosphate nanoparticles; siRNA, small interfering RNA; Scr, scramble. 

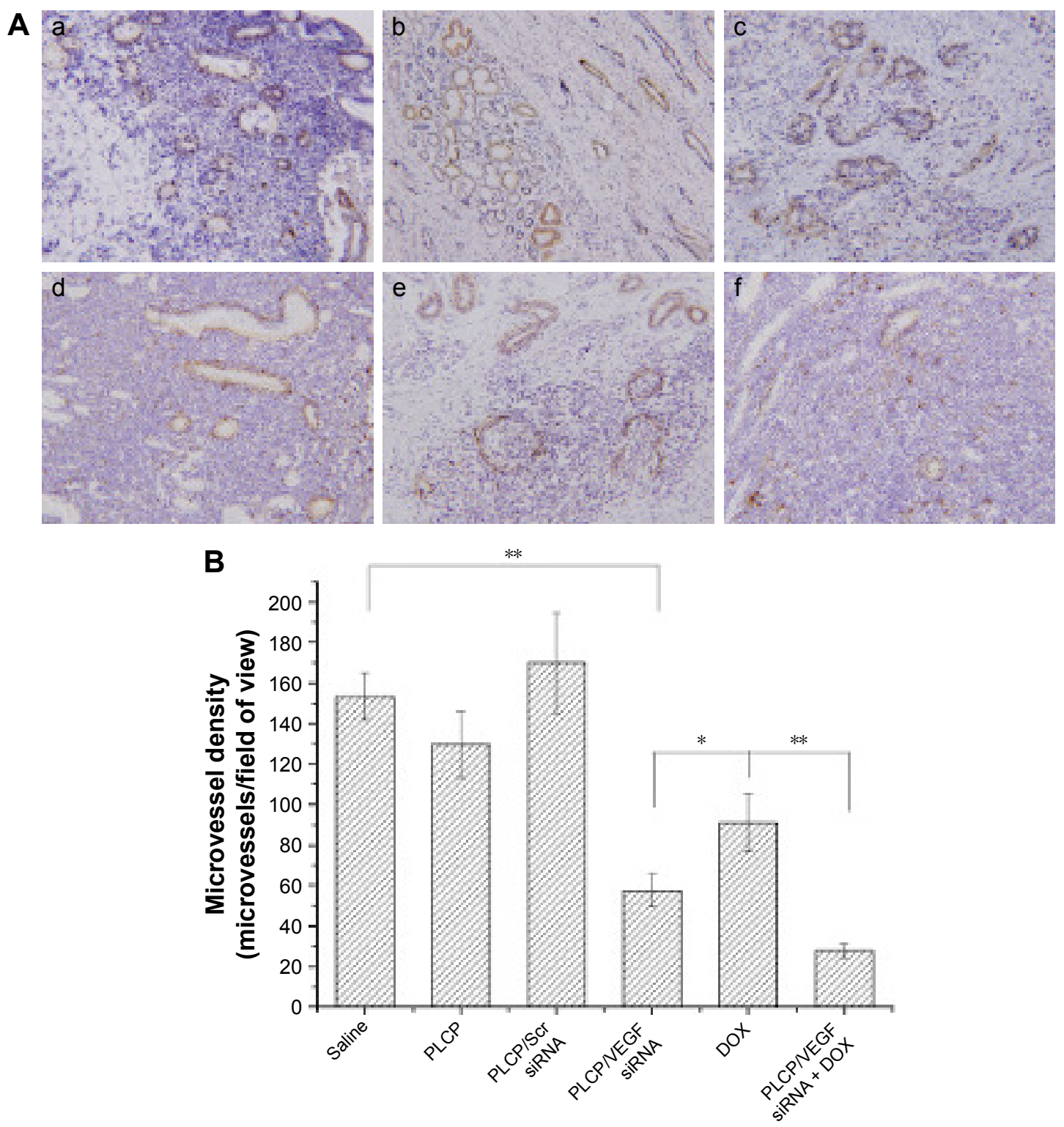

Figure 4 Determination of MVD in tumor xenograft among mice that received different treatments.

Notes: (A) Immunohistochemistry images. (B) Quantitation of MVD. *P<0.05 and **P<0.0I. Saline (a), PLCP (b), PLCP/Scr siRNA (c), PLCP/VEGF siRNA (d), DOX (e), and PLCP/VEGF siRNA + DOX (f)

Abbreviations: DOX, doxorubicin; MVD, microvessel density; PLCP, polycation liposome-encapsulated calcium phosphate nanoparticles; Scr, scramble; siRNA, small interfering RNA.

and DOX (91 microvessels/field of view) groups (Figure 4B). Furthermore, we determined VEGF and HIF-1 $\alpha$ protein expression in tumor tissues. VEGF protein expression was observed at low level when those mice were treated with VEGF siRNA (Figure 5A); however, it was expressed at higher level in control groups (more positive cells which presented in dark brown). Similar immunohistochemistry results of HIF-1 $\alpha$ protein were observed (Figure 5B).

\section{Discussion}

Angiogenesis is known to be necessary for tumor progression. There was an autonomous system of vessels developing under the strict control of stimulating and inhibiting factors in tumor tissues. ${ }^{20}$ VEGF showed a predominant role in tumor angiogenesis. Silencing VEGF expression by RNA interference is expected to be a promising strategy to suppress the tumor growth. siRNA is able to silence its target gene when it is successfully delivered into cytoplasm. ${ }^{21}$ Delivery systems that enhance siRNA localization to the cytoplasm can facilitate gene silencing by siRNA therapeutics. Ideal siRNA delivery systems should be developed to be efficiently internalized by target cells, to allow efficient endosomal escape, and to selectively release siRNA into the cytoplasm. Widely used for the delivery of siRNA are cationic lipids or cationic 


\section{A}
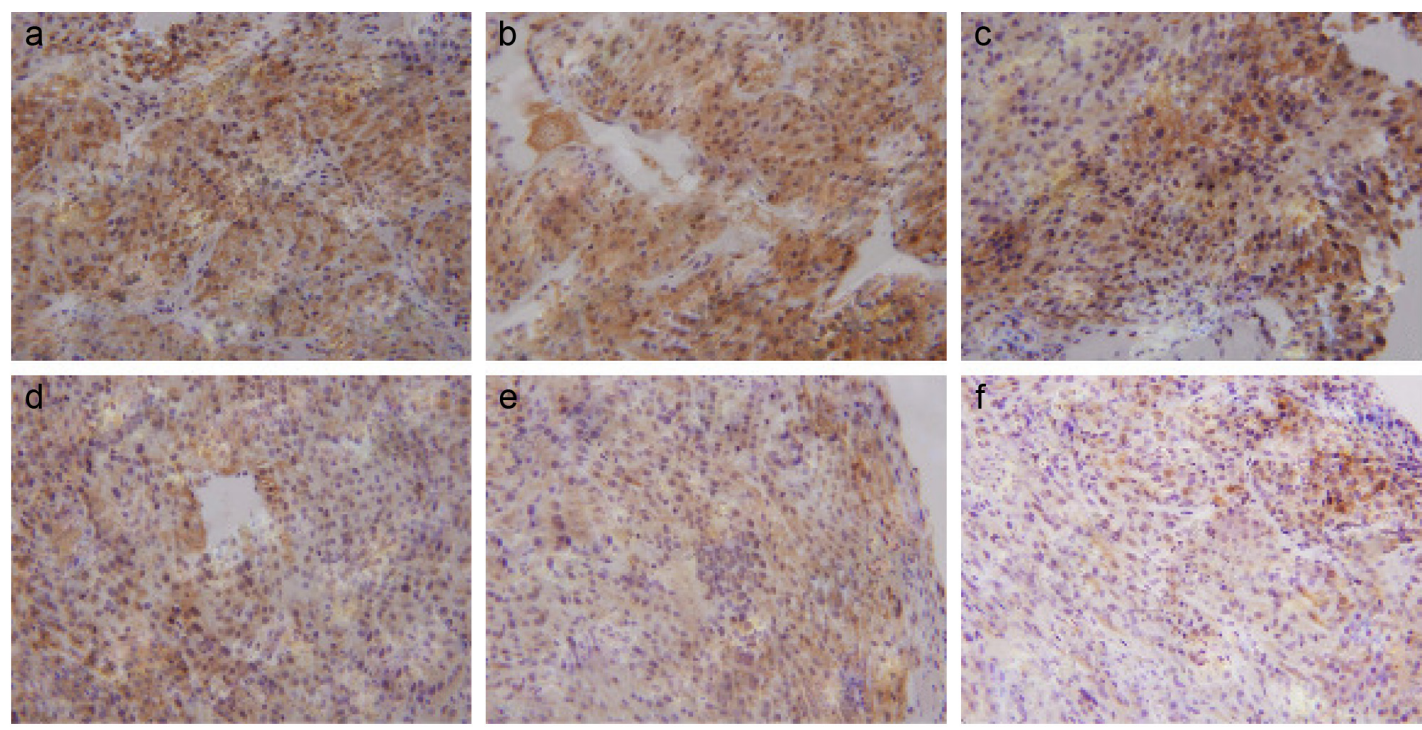

B
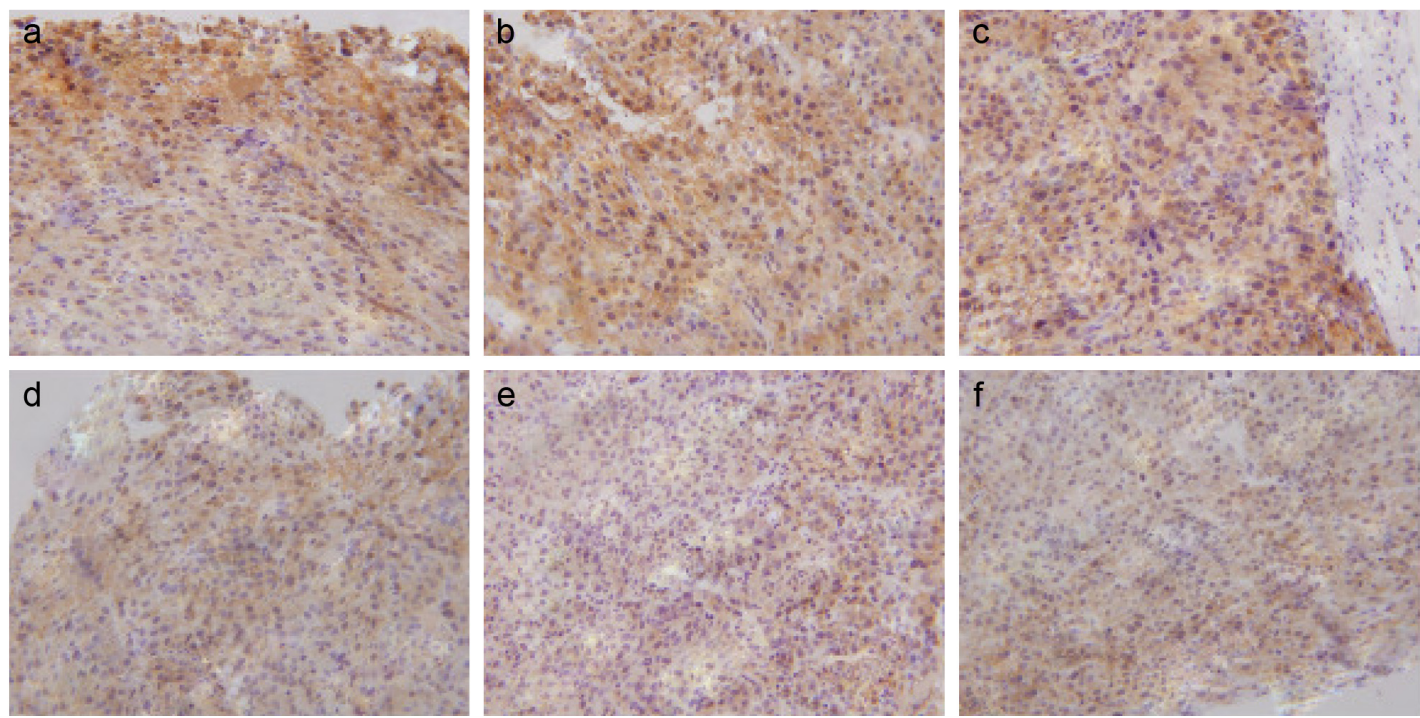

Figure 5 Expression of VEGF and HIF- $\mid \alpha$ by immunohistochemistry.

Notes: Expression of VEGF (A) and HIF-I $\alpha$ (B) in tumor xenograft among mice that received different treatments. Saline (a), PLCP (b), PLCP/Scr siRNA (c), PLCP/VEGF siRNA (d), DOX (e), and PLCP/VEGF siRNA + DOX (f).

Abbreviations: DOX, doxorubicin; HIF-I $\alpha$, hypoxia-inducible factor-I $\alpha$; PLCP, polycation liposome-encapsulated calcium phosphate nanoparticles; Scr, scramble; siRNA, small interfering RNA.

polymers. Recently, various strategies have been utilized to design more complex structure with components of surface, intermediate layer, and core. ${ }^{22}$ These components drive electrostatic interaction with siRNA and increase siRNA loading in vectors. ${ }^{23}$ We have developed a core-membrane siRNA delivery system called PLCP composed of CaP nanoparticles core coated with PCL.

$\mathrm{CaP}$ nanoparticles were considered highly biocompatible and potentially useful in gene delivery $;{ }^{15}$ however, the uncontrollable growth of $\mathrm{CaP}$ precipitates would affect their transfection. ${ }^{24}$ In this study, we did further optimization on the mass ratio of $\mathrm{CaCl}_{2}$ and siRNA to obtain more stable and smaller particle size of $\mathrm{CaP}$ nanoparticles. The results of gel retardation assay indicated that with the increase in mass ratio, the stronger electrostatic interaction between $\mathrm{CaCl}_{2}$ and siRNA was formed (Figure 1B). The addition of sodium citrate could also effectively stabilize $\mathrm{CaP}$ precipitates by specific adsorption of citrate anions onto $\mathrm{CaP}$ nanocrystals, which increases the negative surface charge of $\mathrm{CaP}$ nanoparticles and consequently increases repulsive interparticle forces. ${ }^{25}$ TEM results showed that multiple $\mathrm{CaP}$ nanoparticles are encapsulated into PCL (Figure 1A). We presumed that this special core-membrane structure would further stabilize the precipitation by hydrophobicity of outer lipid bilayer which was consistent with that which $\mathrm{Li}$ et al reported. ${ }^{26}$

The outer lipid bilayer of PLCP could provide effective cellular internalization and endosomal escape by the synergistic effect of PEI and DOPE. ${ }^{18}$ In addition, CaP nanoparticle 
core dissolves in acidic endosomes which increase the osmotic pressure and cause endosomal membrane rupture to release siRNA into cytoplasm. ${ }^{27}$ Compared with commercial reagent, more than two times silencing activity in MCF-7 cells was found when treated with PLCP/VEGF siRNA, as shown in Figure 2A. Gene silencing activity on target mRNA level would be highly sequence specific. It is important to use siRNAs containing functional sequences to reduce the potential for unintended interactions between RNA species. ${ }^{28}$ We designed three different VEGF siRNA sequences, and the RT-qPCR results indicated that VEGF siRNA 2 is the optimal sequence for the subsequent study expecting to reduce undesirable adverse effects. Gene silencing results would reflect on correspondence protein expression finally. There existed a time lag between protein expression and mRNA expression in cells. From the Western blot results (Figure $2 \mathrm{~B}$ and $\mathrm{C}$ ), the weakest VEGF protein strap was observed after $48 \mathrm{~h}$ transfection by PLCP. Although the difference in VEGF protein expression level got close between Lipofectamine 2000/VEGF siRNA and PLCP/ VEGF siRNA, the latter showed superiority in protein inhibition. Free siRNA including VEGF siRNA and random siRNA showed little biological activity due to their instability and fast degradation. ${ }^{29}$

In order to understand the potency of PLCP in tumor inhibition application, VEGF siRNA was delivered into the tumor xenografts. The results demonstrated that PLCP led to a significantly higher tumor growth inhibition than negative control saline (Figure 3), while the use of Scr siRNA showing little tumor inhibition also confirmed the sequence specificity in line with in vitro study. As anticipated, decreased expression of VEGF in tumor tissues was well correlated with the reduced MVD and increased tumor inhibition potency (Figures 4 and 5A). These results suggested that silencing VEGF expression would inhibit angiogenesis efficiently in the early stage of tumor formation and result in tumor growth inhibition. VEGF is a key protein downstream of HIF- $1 \alpha$ under hypoxic conditions. In general, the expression of VEGF is controlled by HIF- $1 \alpha$ in cancer cells. HIF- $1 \alpha$ can activate the expression of the VEGF gene by binding to the hypoxia response element in the VEGF promoter. Then VEGF promotes vascular remodeling under hypoxia conditions. Interestingly, our study found that HIF-1 $\alpha$ level seems to be affected by VEGF as well as in tumor tissues (Figure 5A and B). These results were consistent with those reported by Salva et al. ${ }^{30}$ They found that HIF- $1 \alpha$ inhibition rate can reach $43 \%$ when VEGF gene was knocked down. HIF-1 $\alpha$ expression is induced via activation of PI3K/AKT signaling, which is required for VEGF expression.
Several studies and clinical application experiences have focused on the combination therapy of angiogenesis inhibitor and chemotherapeutics, such as bevacizumab combined with paclitaxel and carboplatin for non-small-cell lung cancer (NSCLC) treatment, ${ }^{31}$ bevacizumab codelivery with DOX for breast cancer treatment, ${ }^{32}$ and co-delivery of VEGF siRNA and DOX by nanocomplexes to human hepatocarcinoma QGY-7703 cells. ${ }^{33}$ However, the combination therapy was still compromised by several obstacles: the overexpression of HIF- $1 \alpha$ resulting from tumor vascular inhibition would induce the enhanced metastasis and drug resistance and systemic toxicity and myelosuppression caused by chemotherapeutics. ${ }^{34}$ Here, we combined VEGF-siRNA and DOX for MCF-7 xenograft treatment. Compared to PLCP/ VEGF siRNA or DOX used alone, the combination therapy can significantly inhibit tumor growth ( 91\%, Figure $3 \mathrm{~B})$ even using $60 \%$ dosage of DOX. Meanwhile, reduced HIF-1 $\alpha$ expression in tumor tissues was also observed, which suggests that metastasis and drug resistance would be decreased.

\section{Conclusion}

In summary, a stable core-membrane siRNA delivery system was developed in order to achieve enhanced tumor angiogenesis inhibition effect. VEGF siRNA mediated by PLCP represented superior capacity of gene silencing, resulting in significant angiogenesis and tumor growth inhibition. These results suggested that delivery of VEGF siRNA via PLCP to inhibit angiogenesis would be a promising approach for breast cancer treatment, especially combined with DOX.

\section{Acknowledgments}

This study was supported by the National Natural Science Foundation of China (NSFC No 81001409 and No 81402872) and Zhejiang Provincial Natural Science Foundation of China (No LY17H300001 and No LY17H160002).

\section{Disclosure}

The authors report no conflicts of interest in this work.

\section{References}

1. Welti J, Loges S, Dimmeler S, Carmeliet P. Recent molecular discoveries in angiogenesis and antiangiogenic therapies in cancer. $J$ Clin Invest. 2013;123(8):3190-3200.

2. Ribatti D, Djonov V. Intussusceptive microvascular growth in tumors Cancer Lett. 2012;316(2):126-131.

3. Carmeliet P, Jain RK. Angiogenesis in cancer and other diseases. Nature. 2000;407(6801):249-257.

4. Ramanathan R, Olex AL, Dozmorov M, Bear HD, Fernandez LJ, Takabe K. Angiopoietin pathway gene expression associated with poor breast cancer survival. Breast Cancer Res Treat. 2017;162(1):191-198. 
5. Jain RK, Duda DG, Clark JW, Loeffler JS. Lessons from phase III clinical trials on anti-VEGF therapy for cancer. Nat Clin Pract Oncol. 2006;3(1):24-40.

6. Lai SR, Andrews LG, Tollefsbol TO. RNA interference using a plasmid construct expressing short-hairpin RNA. Methods Mol Biol. 2007;405:31-37.

7. Barata P, Sood AK, Hong DS. RNA-targeted therapeutics in cancer clinical trials: current status and future directions. Cancer Treat Rev. 2016;50:35-47.

8. Dorsett Y, Tuschl T. siRNAs: applications in functional genomics and potential as therapeutics. Nat Rev Drug Discov. 2004;3(4):318-329.

9. Ofek P, Tiram G, Satchi-Fainaro R. Angiogenesis regulation by nanocarriers bearing RNA interference. Adv Drug Deliv Rev. Epub 2017 Feb 2.

10. Lu JJ, Langer R, Chen J. A novel mechanism is involved in cationic lipid-mediated functional siRNA delivery. Mol Pharm. 2009;6(3): $763-771$.

11. Knudsen KB, Northeved H, Kumar PE, et al. In vivo toxicity of cationic micelles and liposomes. Nanomedicine. 2015;11(2):467-477.

12. Lee K, Bae KH, Lee Y, Lee SH, Ahn CH, Park TG. Pluronic/ polyethylenimine shell crosslinked nanocapsules with embedded magnetite nanocrystals for magnetically triggered delivery of siRNA. Macromol Biosci. 2010;10(3):239-245.

13. Mao S, Sun W, Kissel T. Chitosan-based formulations for delivery of DNA and siRNA. Adv Drug Deliv Rev. 2010;62(1):12-27.

14. Zhou J, Wu J, Hafdi N, Behr JP, Erbacher P, Peng L. PAMAM dendrimers for efficient siRNA delivery and potent gene silencing. Chem Commun. 2006;(22):2362-2364.

15. Maitra A. Calcium phosphate nanoparticles: second-generation nonviral vectors in gene therapy. Expert Rev Mol Diagn. 2005;5(6):893-905.

16. Zhang J, Sun X, Shao R, Liang W, Gao J, Chen J. Polycation liposomes combined with calcium phosphate nanoparticles as a non-viral carrier for siRNA delivery. J Drug Deliv Sci Technol. 2015;30(pt A):1-6.

17. Chen JL, Wang H, Gao JQ, Chen HL, Liang WQ. Liposomes modified with polycation used for gene delivery: preparation, characterization and transfection in vitro. Int J Pharm. 2007;343(1-2):255-261.

18. Chen J, Yu Z, Chen H, Gao J, Liang W. Transfection efficiency and intracellular fate of polycation liposomes combined with protamine. Biomaterials. 2011;32(5):1412-1418.

19. Weidner N, Semple JP, Welch WR, Folkman J. Tumor angiogenesis and metastasis - correlation in invasive breast carcinoma. NEngl J Med. 1991;324(1):1-8.

20. Bergers G, Benjamin LE. Tumorigenesis and the angiogenic switch. Nat Rev Cancer. 2003;3(6):401-410.
21. He S, Zhang D, Cheng F, Gong F, Guo Y. Applications of RNA interference in cancer therapeutics as a powerful tool for suppressing gene expression. Mol Biol Rep. 2009;36(8):2153-2163.

22. Kim HJ, Kim A, Miyata K, Kataoka K. Recent progress in development of siRNA delivery vehicles for cancer therapy. Adv Drug Deliv Rev. 2016;104:61-77.

23. Rao NM. Cationic lipid-mediated nucleic acid delivery: beyond being cationic. Chem Phys Lipids. 2010;163(3):245-252.

24. Kakizawa Y, Furukawa S, Kataoka K. Block copolymer-coated calcium phosphate nanoparticles sensing intracellular environment for oligodeoxynucleotide and siRNA delivery. J Control Release. 2004; 97(2):345-356.

25. Leeuwenburgh SC, Ana ID, Jansen JA. Sodium citrate as an effective dispersant for the synthesis of inorganic-organic composites with a nanodispersed mineral phase. Acta Biomater. 2010;6(3):836-844.

26. Li J, Yang Y, Huang L. Calcium phosphate nanoparticles with an asymmetric lipid bilayer coating for siRNA delivery to the tumor. J Control Release. 2012;158(1):108-114.

27. Kovtun A, Heumann R, Epple M. Calcium phosphate nanoparticles for the transfection of cells. Biomed Mater Eng. 2009;19(2-3):241-247.

28. Gorski SA, Vogel J, Doudna JA. RNA-based recognition and targeting: sowing the seeds of specificity. Nat Rev Mol Cell Biol. 2017;18(4): 215-228.

29. Selvam C, Mutisya D, Prakash S, Ranganna K, Thilagavathi R. Therapeutic potential of chemically modified siRNA: recent trends. Chem Biol Drug Des. Epub 2017 Apr 5.

30. Salva E, Turan SO, Eren F, Akbuga J. The enhancement of gene silencing efficiency with chitosan-coated liposome formulations of siRNAs targeting HIF-1 alpha and VEGF. Int J Pharm. 2015;478(1):147-154.

31. Yamasaki M, Murakami I, Nakano K, et al. Carboplatin plus weekly paclitaxel combined with bevacizumab as first-line treatment for nonsmall cell lung cancer. Anticancer Res. 2017;37(2):923-928.

32. Tang Y, Soroush F, Tong Z, Kiani MF, Wang B. Targeted multidrug delivery system to overcome chemoresistance in breast cancer. Int $J$ Nanomedicine. 2017;12:671-681.

33. Han L, Tang C, Yin C. Dual-targeting and $\mathrm{pH} /$ redox-responsive multilayered nanocomplexes for smart co-delivery of doxorubicin and siRNA. Biomaterials. 2015;60:42-52.

34. Feng Q, Yu MZ, Wang JC, et al. Synergistic inhibition of breast cancer by co-delivery of VEGF siRNA and paclitaxel via vapreotide-modified core-shell nanoparticles. Biomaterials. 2014;35(18):5028-5038. 


\section{Supplementary materials}

A

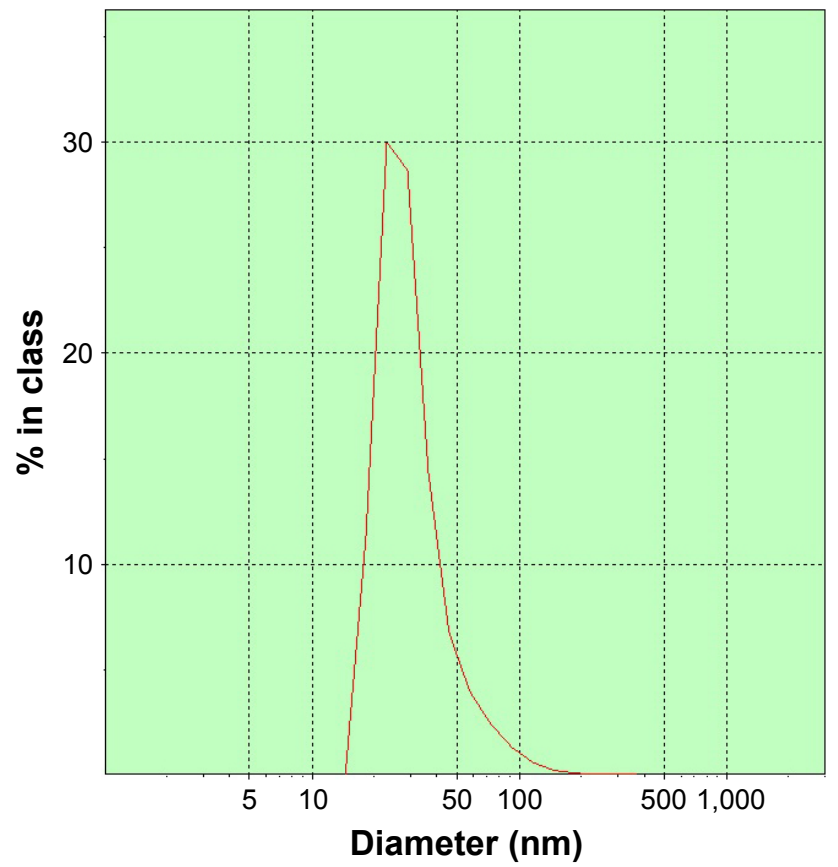

B Size distribution(s)

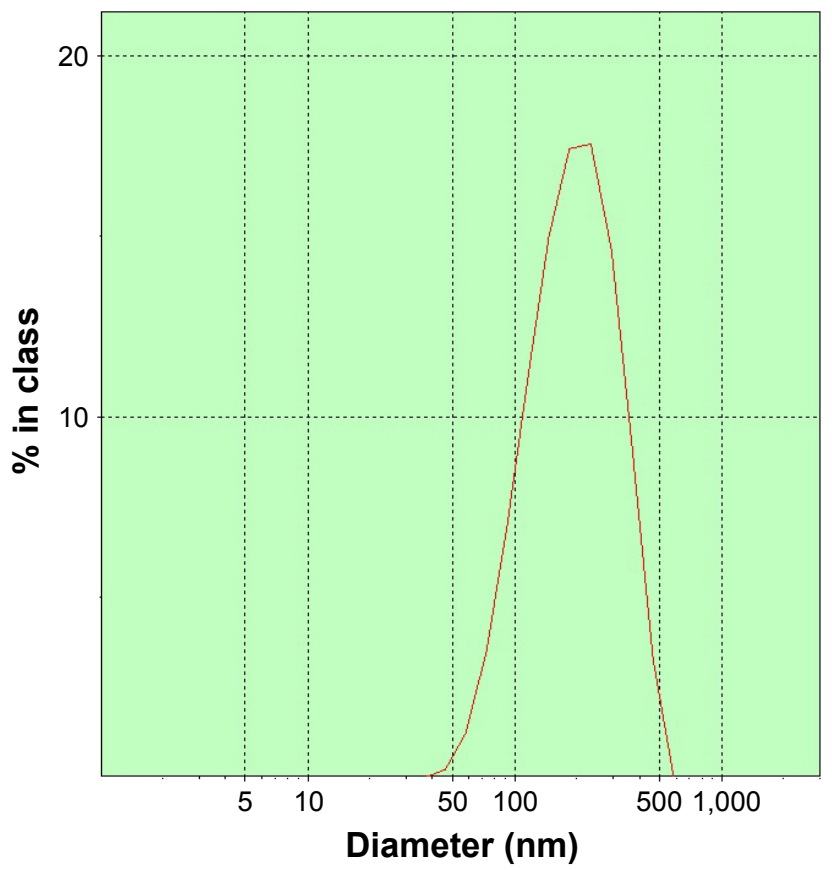

C

Size distribution(s)

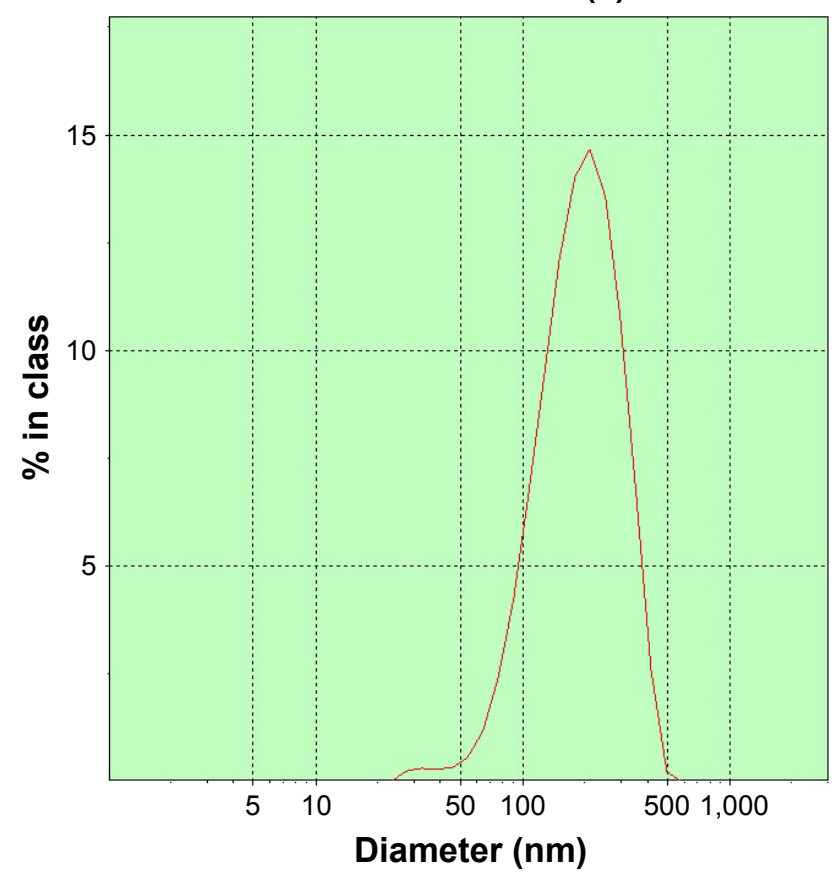

Figure SI Size distribution measured by laser diffraction spectrometry.

Note: Size distribution of CaP nanoparticles (A), PCL (B), and PLCP (C).

Abbreviations: $\mathrm{CaP}$, calcium phosphate; PCL, polycation liposomes; PLCP, polycation liposome-encapsulated calcium phosphate nanoparticles. 
A

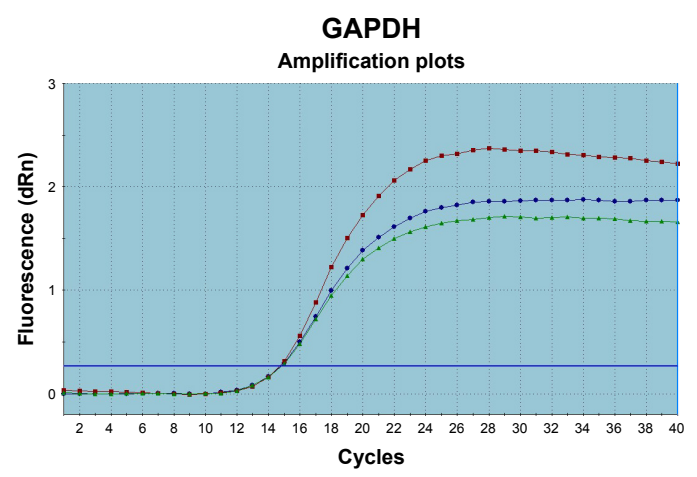

B

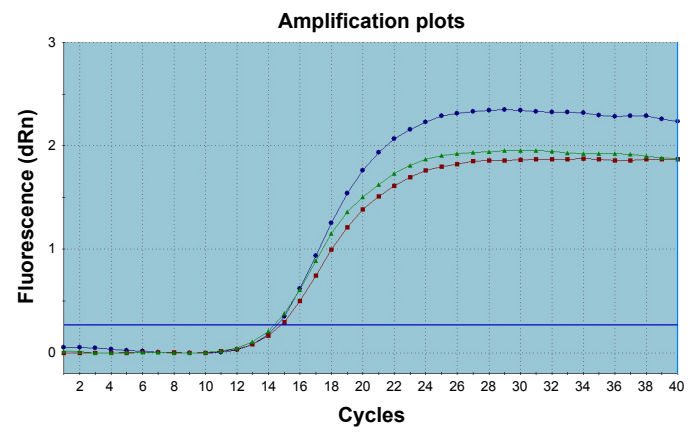

C

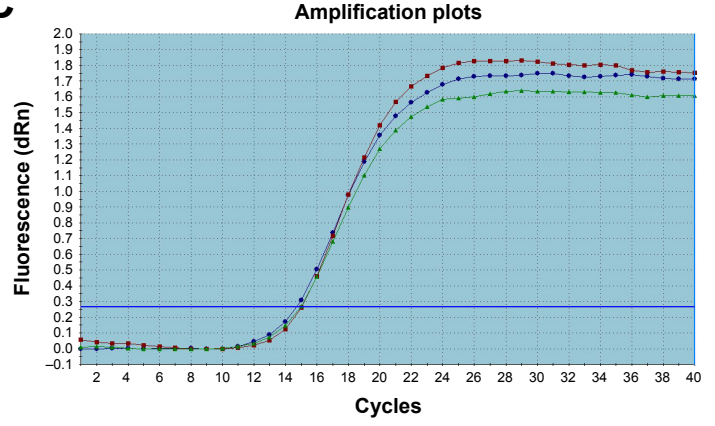

D

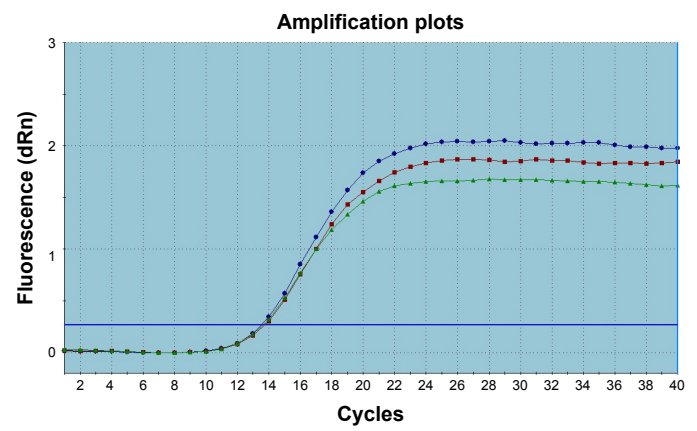

VEGFA

Amplification plots

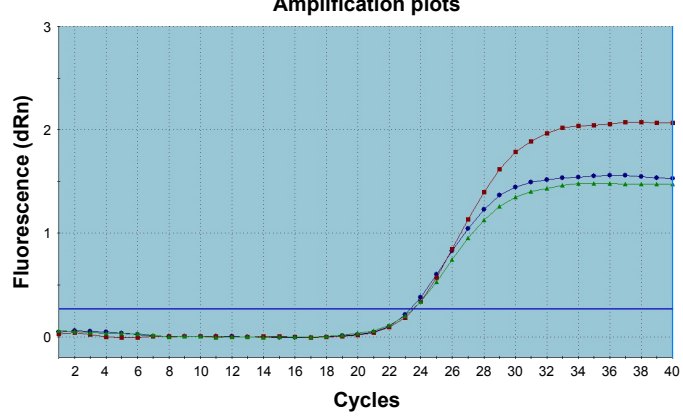

Amplification plots

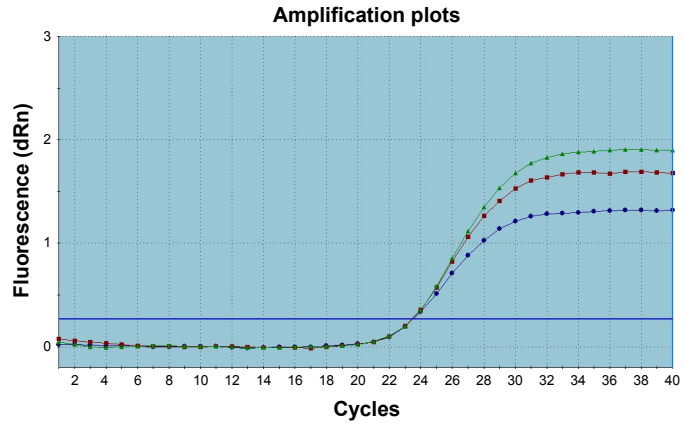

Amplification plots

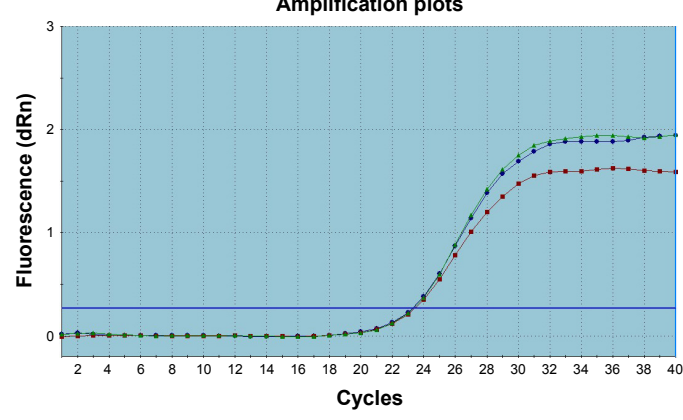

Amplification plots

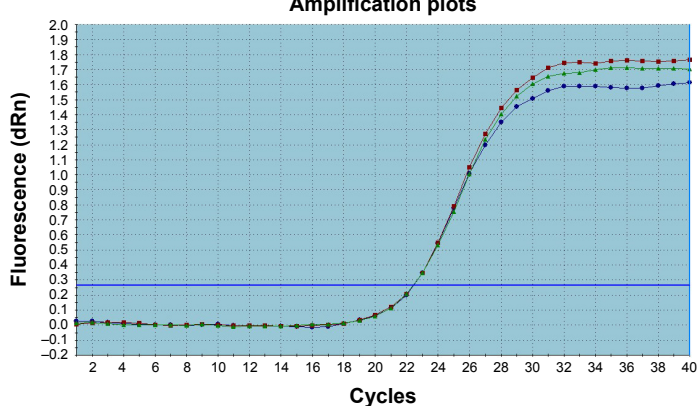

Figure S2 (Continued) 
E

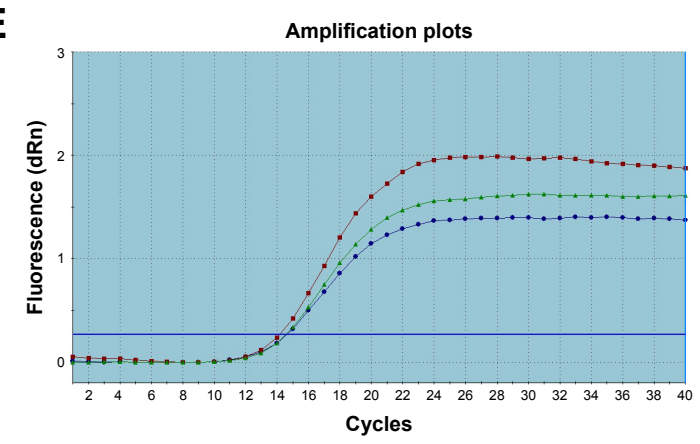

$\mathbf{F}$

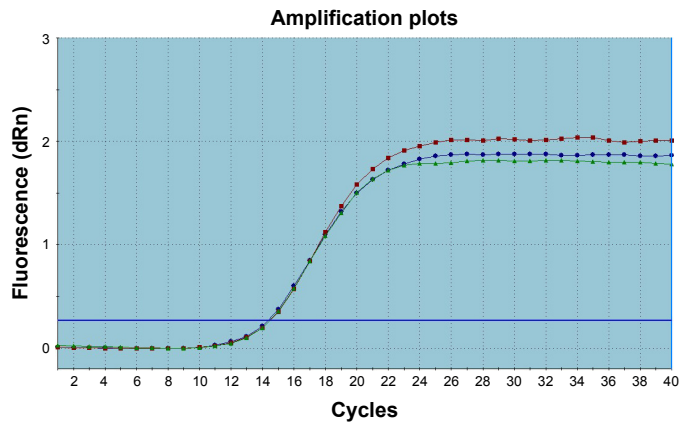

G

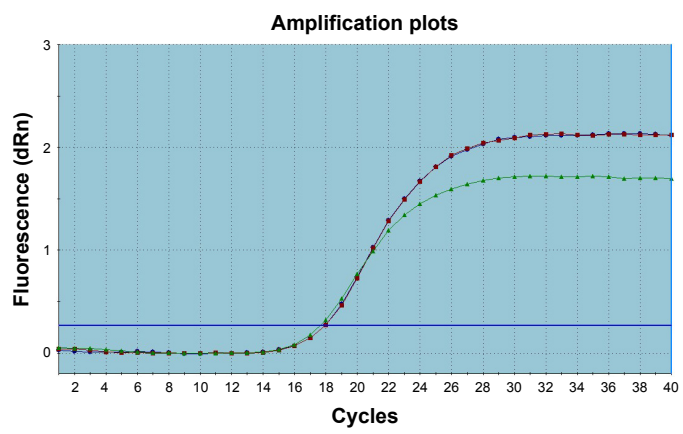

H

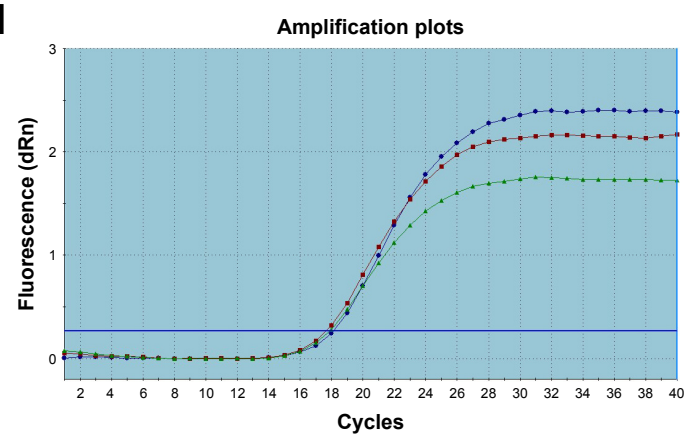

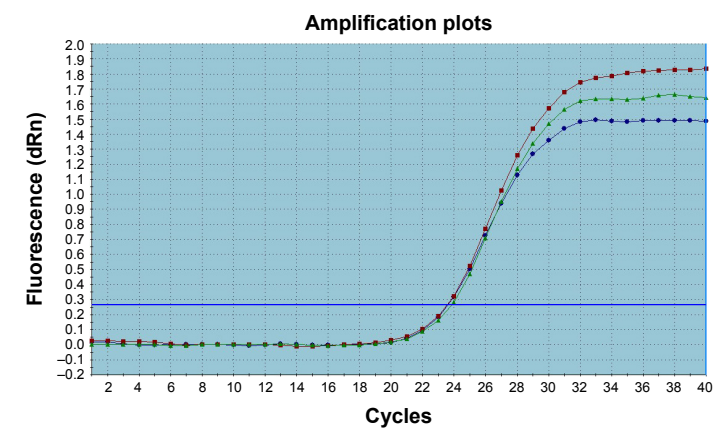
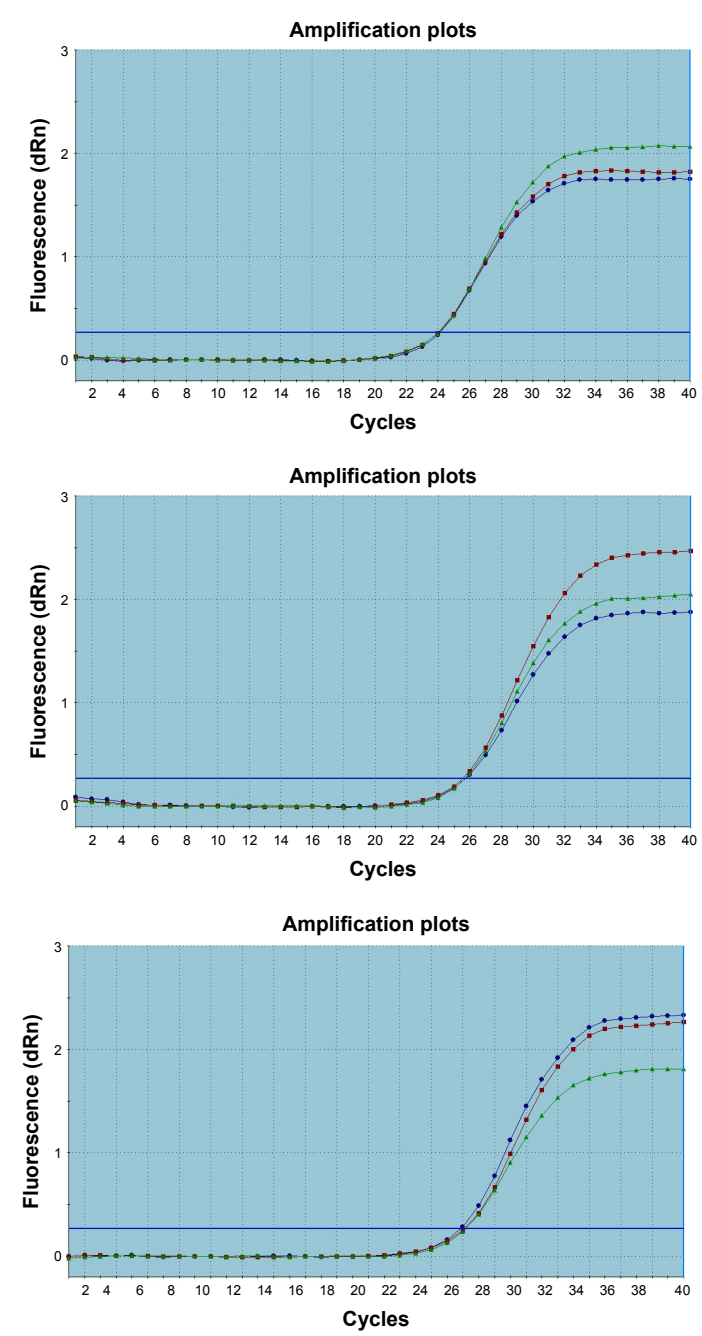

Figure S2 (Continued) 

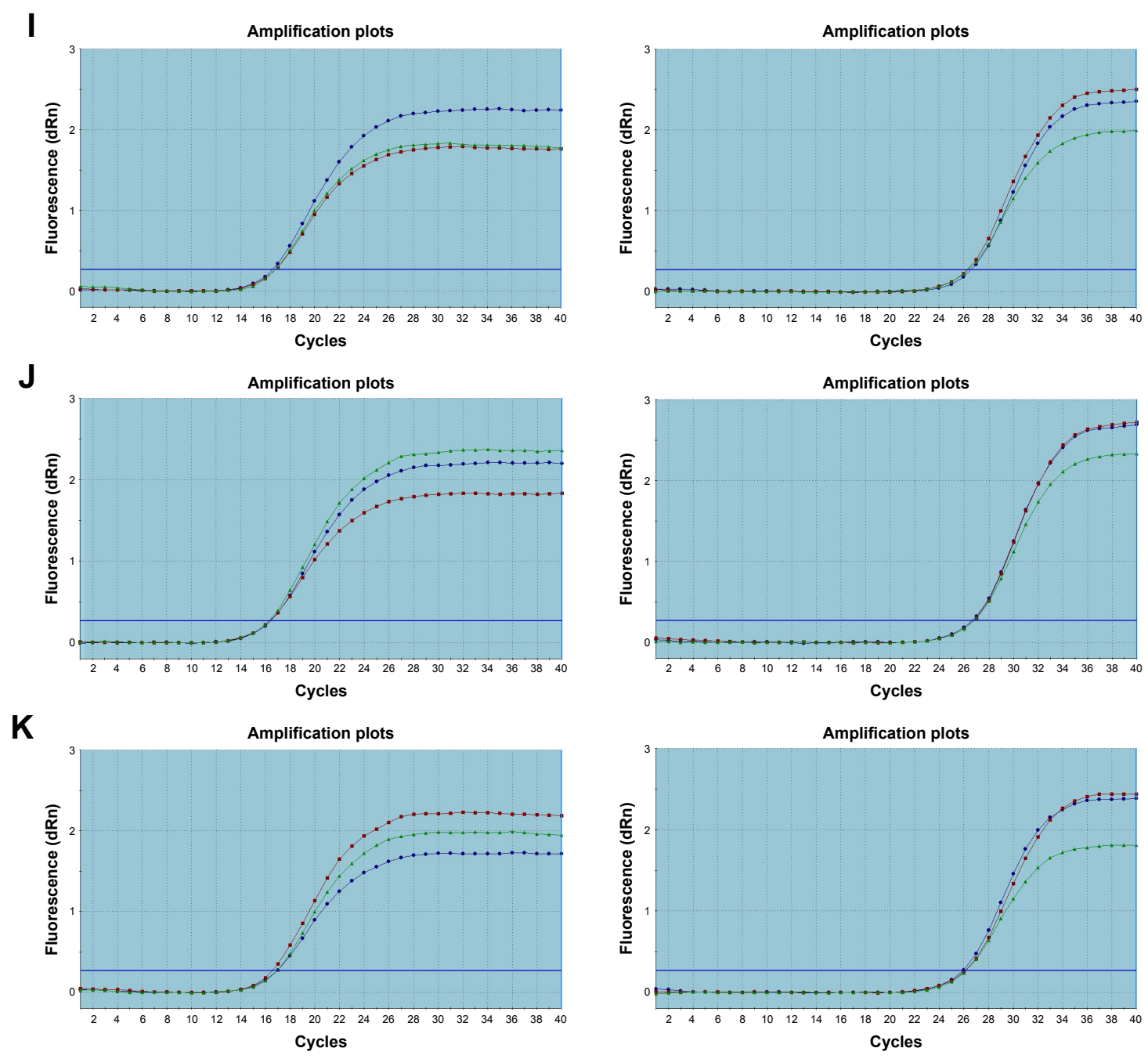

Figure S2 Amplification curves for RT-qPCR.

Notes: (A) Control. (B) Lipofectamine 2000. (C) Lipofectamine 2000 + random siRNA. (D) Lipofectamine 2000 + VEGF-siRNA I. (E) Lipofectamine $2000+$ VEGF-siRNA 2. (F) Lipofectamine 2000 + VEGF-siRNA 3. (G) PLCP. (H) PLCP + random siRNA. (I) PLCP + VEGF-siRNA I. (J) PLCP + VEGF-siRNA 2. (K) PLCP + VEGF-siRNA 3.

Abbreviations: GAPDH, glyceraldehyde-3-phosphate dehydrogenase; PLCP, polycation liposome-encapsulated calcium phosphate nanoparticles; RT-qPCR, real-time quantitative polymerase chain reaction; siRNA, small interfering RNA.

\section{Publish your work in this journal}

The International Journal of Nanomedicine is an international, peerreviewed journal focusing on the application of nanotechnology in diagnostics, therapeutics, and drug delivery systems throughout the biomedical field. This journal is indexed on PubMed Central, MedLine, CAS, SciSearch ${ }^{\circledR}$, Current Contents ${ }^{\circledR} /$ Clinical Medicine,

\section{Dovepress}

Journal Citation Reports/Science Edition, EMBase, Scopus and the Elsevier Bibliographic databases. The manuscript management system is completely online and includes a very quick and fair peer-review system, which is all easy to use. Visit http://www.dovepress.com/ testimonials.php to read real quotes from published authors. 